\title{
APOCALIPSES NARRATIVOS, AUTORAIS E EDITORIAIS COM ERIC NOVELLO
}

APOCALYPSES: NARRATIVE, AUTHORSHIP, AND THE PUBLISHING WORLD - AN INTERVIEW WITH ERIC NOVELLO

Eric Novello

ENTREVISTA POR:

Melissa de Sá* melissacdesa@gmail.com

Doutoranda em Literaturas de Língua Inglesa pela Universidade Federal de Minas Gerais (UFMG) e mestre pela mesma instituição. Professora de língua inglesa no Instituto Federal de Minas Gerais (IFMG)

Eric Novello é autor dos romances Ninguém nasce herói (Seguinte, 2017), Exorcismos, amores e uma dose de blues (Gutenberg, 2014) e Neon azul (Draco, 2012). É tradutor de romances e quadrinhos e formado pela Escola de Cinema Darcy Ribeiro. Presença marcante no cenário da literatura brasileira contemporânea, Novello apresenta narrativas potentes com elementos do fantástico e do insólito que abordam a crueza da experiência da juventude e da mortalidade. Nessa breve conversa, discutimos a ideia de apocalipse e distopia focando em seu romance mais recente.
JAMES BERGER DEFINE APOCALIPSE COMO TODO EVENTO OUE DIVIDE O MUNDO EM UM 'ANTES' E UM 'DEPOIS'. COMO NINGUÉM NASCE HERÓI SE RELACIONARIA COM ESSA DEFINIÇÃO?

Eric Novello: No "Ninguém Nasce Herói” minha ideia era explorar o aspecto cinza das novas ditaduras, mostrar justamente a falta de clareza de um antes e depois. Certa vez li a entrevista de uma jovem que morava em um país autoritário e ela dizia que a sua rotina antes e depois da ditadura era muito parecida. Ela saía para trabalhar, saía para ver os amigos, estudar, voltava para a casa. Nos fins de semana, ia se divertir. A diferença é que às vezes alguns a migos desapareciam, ou que você passava a só expressar suas opiniões verdadeiras perto de pessoas de confiança. Esse texto me marcou muito. Porque é isso o que acontece. As diferenças estão nos menores detalhes. Eu posso viver em uma democracia enquanto alguém, no mesmo 
país, vive em áreas onde essa democracia não chega, áreas dominadas pelo tráfico, por milícias, áreas sem água encanada. Depois do lança mento do livro, era muito comum ver leitores falando "ué, mas se é uma ditadura cadê os tanques na rua?”. Símbolos que usamos como referência Outras vezes leitores comentavam "espero que isso nunca aconteça", se referindo justamente a cenas inspiradas em notícias recentes. Ou seja, mais uma vez, o que uns tomam como referência de um futuro distópico para outros já é parte do cotidiano.

A DISTOPIA COMO GÊNERO LITERÁRIO VEM EM ONDAS AO LONGO DO SECULO XX, RESPONDENDO A DIFERENTES QUESTIONAMENTOS POLÍTICOS E SOCIAIS. COMO VOCÊ VÊ A RETOMADA DA DISTOPIA NESSE COMEÇO DE SÉCULO XXI?

Eric Novello: Para a minha geração, pelo menos, o século XXI sempre foi o paradigma de futuro. E, de repente, nós chegamos ao futuro e ele não é exatamente o que esperávamos. Nossa qualidade de vida avançou, no todo e também para minorias políticas, mas ficamos longe do que imagináva mos, obvia mente. A genética não criou uma revolução mágica na medicina, HIV ainda assombra pessoas sexualmente ativas, a sífilis teve um retorno. O petróleo continua movendo guerras, carros continuam poluindo o mundo e nem voar eles voam. O clima enlouqueceu (com seus motivos). Para piorar, o fanatismo religioso foi ocupando esses espaços de dúvida e transformou a ciência em uma espécie de vilã. É a revolta da vacina 2.0. Então, esse distanciamento entre a realidade que nos cerca e a expectativa que tínhamos do futuro me parece um bom combustível dessa retomada, porque ela amplia a sensação de que vivemos tempos sombrios, sem lançar luz nos nossos avanços. Sinceramente, espero que autores de ficção científica não distópicos consigam direcionar nosso olhar para os séculos além e nos ajudem a sair dessa armadilha que é acreditar que o futuro chegou.

VOCÊ JÁ PUBLICOU UM ROMANCE ADULTO, NEON AZUL. O PROCESSO DE ESCRITA PARA O PÚBLICO ADULTO E JOVEM É DIFERENTE? COMO VOCÊ CONSIDERA QUESTÕES COMO ADEQUACÃO DE LINGUAGEM, TEMÁTICA E CENSURA? EXISTE ESSA PREOCUPAÇÃO NA ELABORAÇÃO DA OBRA?

Eric Novello: Essa é uma curiosidade comum das pessoas, a questão da censura. O young adult fala de vários assuntos tabus, porém muito pertinentes para o público adolescente e jovem adulto. Então é mais uma questão de perceber a melhor abordagem do que correr o risco de que sua editora vete um determinado assunto. Gosto de recorrer ao exemplo da separação de pais. Se você é criança, você não entende o que está acontecendo, pode a té sentir que fez algo errado e isso causou a separação. Então esse seria um ponto interessante para se trabalhar com um
EM TESE
BELO HORIZONTE
v. 24
N. 2
MAIO-AGO. 2018

NOVELLO; SÁ. Apocalipses narrativos, autorais e editoriais com Eric Novello

$226-232$ 
leitor mais novo. Se você é adolescente, as consequências já são diferentes. Talvez você carregue alguma raiva mal resolvida por causa do processo de troca de lar ou já se de bem com o novo namorado ou namorada dos seus pais. Um livro young adult poderia explorar que sequelas uma separação deixa em um jovem, por exemplo, ou mostra esse lar saudável onde a separação não é mais um grande problema. Se você é adulto, bem, talvez isso até renda uma comédia daquelas onde as duas famílias se encontram para a festa de Natal e precisam se entender. Ou quem sabe as duas famílias se odeiem e isso gere um fim de semana de crimes e assassinatos numa história policial, que, imagino eu, não seria aceita numa versão young adult. Se esta mos falando especificamente de sexo, volto à questão da abordagem. Em Exorcismos, Amores e Uma Dose de Blues existe uma cena de sexo feita para deixar o leitor excitado. Ponto. É uma cena imersiva narrada por um protagonista bissexual, o que quebra algumas fronteiras de libido para diferentes tipos de leitores. Em um jovem adulto, se eu escrevesse uma cena de sexo, seria para ajudar a normalizar o assunto para o público desse nicho, para mostrar que não há nada de errado em sentir desejo e que é possível lidar com isso sem culpa, de maneira natural. Quem sabe até mesmo ajudar a tirar algumas dúvidas a respeito. Isso quer dizer que a editora aceitaria sem problemas? A minha sim. Se fosse uma editora que publica pensando somente em vender livros para escolas... Talvez aí fosse diferente considerando a situação atual do país e o fato de muitas escolas religiosas não terem um direcionamento progressista.

A DIVISÃO ENTRE ALTA LITERATURA E LITERATURA POP AINDA SE MOSTRA MUITO EVIDENTE NO BRASIL TANTO POR PARTE DA CRÍTICA QUANTO POR PARTE DOS EDITORES. PARA VOCÊ COMO AUTOR, COMO FICA ESSA OUESTÃO? ALGUMA PERSPECTIVA OUANTO À EXISTÊNCIA OU NÃO DESSA CATEGORIZAÇÃO DA LITERATURA NO FUTURO?

Eric Novello: Queria ser um espírito evoluído e dizer que não me abalo com essa divisão, mas a verdade é que penso nisso o tempo inteiro. Algumas vezes de um jeito ruim, tentando forçar minha mente criativa numa direção que não é a minha só para tentar fazer parte de um clubinho que eu desprezo como autor (embora goste como leitor). Mas na maior parte do tempo é ruim simplesmente porque editores se acostumaram a etiquetas e eles precisam entender para quem o autor está escrevendo, para que público eles poderão vender os livros e eu sou um habitante da fronteira. Meus livros têm um pé no realismo e um no insólito, têm um pé cravado na literatura pop e outro nos experimentos de linguagem mais associados à alta literatura. Porque é isso que eu sei fazer, é esse o meu processo natural de escrita, de visão do mundo, o resultado do meu 
liquidificador de referências. Queria ter o desprendimento de um David Lynch, ídolo máximo, e seguir minhas loucuras sem racionalizar demais sobre elas, ou a facilidade de um Stephen King de sair escrevendo sem se preocupar com público ou ta manho final, mas acho que deve ser mais fácil fazer isso quando já se tem fama e o bolso cheio de dinheiro. Sobre o futuro, queria ter essa resposta para dar de maneira mais concreta, mas só tenho mesmo o meu otimismo de que a situação venha a mudar.

TODOS OS SEUS LIVROS FORAM PUBLICADOS EM FORMATO DIGITAL, INCLUINDO CONTOS EM FORMATO E-BOOK SOLO. VOCÊ ACREDITA QUE O LIVRO DIGITAL TEVE ALGUM IMPACTO NO MERCADO EDITORIAL BRASILEIRO? E NOS LEITORES?

Eric Novello: Recentemente saímos de uma política que era insuficiente para a formação de novos leitores para uma que visa o estrangulamento da estrutura de ensino e cultura do país através do corte de verbas, entre outras ações. Esta mos passando pela falência de duas grandes redes de livrarias, cuja geração atual de donos não foi capaz de conduzir uma boa administração. Com a reforma trabalhista, a profissão de livreiro foi terceirizada em alguns pontos de venda, criando o livreiro freelancer, alguém que está na loja num dia e no outro em outro emprego, o que impossibilita que o vendedor conheça todos os livros que estão sendo procurados. $\mathrm{O}$ efeito disso nas editoras, obviamente, foi um endividamento que vai encolher a lista de lançamentos por alguns anos. Essa soma de forças é esmagadora para o mercado editorial, já que o livro de papel é e provavelmente sempre será o pilar da literatura.

Mas - pausa para respirar - e-books têm a sua relevância e ajudam a contornar essa situação. Para editoras independentes, torna viável lançar novos autores e não depender da cadeia de distribuição de livros físicos. Editoras grandes têm deixado disponível em e-book livros esgotados em papel, apelando às vezes para um sistema de impressão on demand, o que também ajuda na circulação de conhecimento. Já vi casos de séries que foram canceladas por vendas baixas e a editora, em respeito aos leitores, publicou o que faltava em e-book, um bom exemplo de diálogo nessa relação editora-leitor. Autores independentes podem começar a construir uma rede de leitores disponibilizando ou vendendo seu material em e-books. Estrategicamente, um autor pode la nçar contos passados no universo do seu livro antes de publicar o livro em si, manter a história viva entre um livro e outro. Mesmo que as vendas não sejam grandes, o burburinho vale por si só.

Dá para ver que o e-book é um forma to muito versátil, que pode se adequar a vários projetos diferentes e isso, claro, se reflete nos leitores. Porém, enfatizo mais uma vez, que sem um governo que entenda a importância dos 
investimentos em cultura e educação (ou que entenda sem usar isso para o mal), não existe milagre que dê jeito. $\mathrm{O}$ e-book é um balde, mas o buraco no barco continua lá e a água continua entrando.

O YOUNG ADULT AINDA É VISTO COM RESSALVAS NO AMBIENTE ACADÊMICO, FREQUENTEMENTE RELEGADO A DEBATES MARGINAIS SOBRE LITERATURA INFANTIL. COMO VOCÊ ENXERGA O GÊNERO E SUAS CARACTERÍSTICAS? NO OUE O YOUNG ADULTSE DIFERE DA LITERATURA ADULTA E INFANTIL?

Eric Novello: young adult é um nicho muito corajoso Essa literatura voltada para o jovem adulto explora tema e situações delicados como suicídio, depressão, distúrbios alimentares, direitos de minorias, preconceitos dos mais diversos, violência policial, autoimagem, governos autoritários. Junto a isso coloca muitos grupos marginalizados que nem sequer são considerados em outros nichos literários como protagonistas, donos de suas histórias e merecedores de finais felizes. E essa diversidade representada na ficção está começando a se fazer presente também entre os autores, o que é fundamental. Não bastasse oxigenar as histórias e fomentar debates, a literatura young adult ainda é uma poderosa formadora de novos leitores. Algo que, alguns autores considerados literários e aqueles que os estudam às vezes se esquecem, não surge por geração espontânea.
TENDO SE FORMADO EM CINEMA, COMO É A RELAÇÃO ENTRE IMAGEM E PALAVRA EM SUAS OBRAS?

Eric Novello: Depois de publicar meus dois primeiros livros, decidi que precisava aprimorar não só minhas ferra mentas de trabalho como expandir meus horizontes culturalmente. Não via nada que me atraísse em oficinas de escrita, então fui fazer escola de cinema. Para minha sorte, todos os meus professores fugiam de um esquema formulaico de ensino e passara $\mathrm{m}$ longe de manuais no estilo Syd Field. Na maior parte do tempo estávamos assistindo filmes fora do espectro comercial, indo do cinema italiano ao cinema russo, passando pelo independente a merica no, estudando cinema brasileiro. Filmes que, em outras palavras, escapavam da fórmula hollywoodiana. E no cinema, lógico, essa fuga de uma fórmula vai além da estrutura do roteiro, ela está na fotografia, na montagem, no que o diretor escolhe mostrar para o espectador. A literatura não precisa ser visual. $\mathrm{O}$ que se chama de alta literatura raramente é. Mas para mim, se tornou inescapável pensar em como as palavras se traduzem em imagens e que proveito eu posso tirar disso para criar uma leitura imersiva. Sigo explorando essa brincadeira, experimentando diferentes recursos, e acho que ainda estou bem longe de conseguir um resultado que me satisfaça por completo. Mas de algum modo sei que isso é transmitido para o leitor, porque costumo ouvir que meus livros são bastante "visua is".
EM TESE
BELO HORIZONTE
v. 24
N. 2
MAIO-AGO. 2018

NOVELLO; SÁ. Apocalipses narrativos, autorais e editoriais com Eric Novello

$226-232$ 
NINGUÉM NASCE HERÓl APRESENTA COMO TEMA CENTRAL A QUESTÃO DA REPRESENTATIVIDADE E A IMPORTÂNCIA DISSO PARA A CONSTRUÇÃO DE UMA IDENTIDADE. COMO VOCÊ VÊ SEUS PROTAGONISTAS NESSA RELAÇÃO?

Eric Novello: No Ninguém Nasce Herói todo o ecossistema de personagens lida com a questão da diversidade, mas eles são mais do que isso. Estão todos ali pensando no futuro, em estudo, emprego, em sair para se divertir, falar de seus namoros, beijos na boca. A diversidade se destaca quando alguém de fora aponta o dedo para um desses personagens e diz "você é diferente de mim, não merece ser tratado com o mesmo respeito". Costumo dizer meio na brincadeira meio fala ndo sério que só lembro que sou gay quando alguém fala isso para mim, e quis passar esse sentimento para o livro. No caso do Chuvisco, o protagonista, ele é um menino cis se descobrindo demissexual e possivelmente bissexual, e isso é usado para mostrar o quanto é importante para alguém entender essas partes de si e o quanto, num a mbiente conservador, faz falta um maior debate para facilitar esse entendimento.

NARRATIVAS DISTÓPICAS, PARA VOCÊ, PODEM CONTRIBUIR PARA O DEBATE DE UM FUTURO MELHOR?

Eric Novello: Todo livro é, de certo modo, um retrato do presente, do momento em que foi escrito. Seja um romance histórico ou uma distopia, olhe para frente ou para trás, os anseios do autor são sempre contemporâneos. Me parece um contágio inevitável. Então, nesse sentido, é um debate que abrange a literatura como um todo. $\mathrm{O}$ que a distopia faz, seja lá em que época ou mundo ela se passe, é colocar com mais vontade o dedo na ferida, despir de sutilezas os problemas que nos cercam. O que pode facilitar o surgimento dessa faísca incendiária do debate.

COMO É ESSA EXPERIÊNCIA DE IMAGINAR UM BRASIL DISTÓPICO?

Eric Novello: Muito similar a acompanhar as notícias nos jornais ou passar uma hora em algumas redes sociais! Escrever Ninguém Nasce Herói foi basta nte desgastante nesse sentido. Havia dias em que eu terminava de escrever esgotado, com vontade de chorar, e precisava me forçar a levar meus pensamentos para um lugar mais confortável. Eu sabia racionalmente que era uma nuvem negra alimentada pelo livro, mas ainda assim era difícil lidar com ela. Conforme a situação política do país foi saindo dos eixos, sentia como se a realidade estivesse me alcançando, o que tornou a experiência mais sufocante. Quando terminei o livro, prometi a mim mesmo que passaria um tempo longe desse tipo de história e, embora fique tentado a voltar ao mundo do livro, sempre espero a vontade passar e finjo que ela não existiu. 
NINGUÉM NASCE HERÓI ESTABELECE UM PARALELO INTERESSANTE COM OS ROMANCES SOBRE A DITADURA NO BRASIL. AINDA QUE SEJA UMA EXTRAPOLAÇÃO DISTÓPICA, É FÁCIL PARA O LEITOR SE REMETER A ESSAS OBRAS DURANTE A LEITURA DO LIVRO. PARA VOCÊ, HÁ AÍ UM DIÁLOGO POSSÍVEL?

Eric Novello: Quando escrevi o Ninguém Nasce Herói estava pensando na nossa situação a tual, simplesmente. Mas eu nasci ainda na ditadura e era muito claro para mim o medo nos olhos dos meus professores quando falávamos sobre Brasil na sala, apesar de ser criança. Mesmo com a virada democrática, o medo demorou a desaparecer. $\mathrm{E}$ essa fotografia, essa memória, foi algo que ca rreguei comigo. Assim, no que me diz respeito, é um diálogo construído mais através das vivências do passado e do presente do que pelo caminho da literatura, embora o produto final seja o mesmo. O final de um dos personagens do livro remete diretamente ao final de muita gente que foi morta pela ditadura, por exemplo. O desaparecimento. Um corpo que nunca é encontrado para que a família possa enterrá-lo. Mas se formos pensar em violência policial, milícias e tráfico, essa não é uma situação tão incomum. Mais uma vez, uma conexão por vivências do passado e do presente referentes a uma tragédia política da qual o Brasil jamais conseguiu se desvencilhar. 